\title{
Effect of add-on direct renin inhibitor aliskiren in patients with non-diabetes related chronic kidney disease
}

\author{
Szu-yuan Li ${ }^{1,2^{*}+}$, Yung-Tai Chen ${ }^{1,3+}$, Wu-Chang Yang ${ }^{1,4}$, Der-Cherng Tarng ${ }^{1,5}$, Chih-Ching Lin ${ }^{1,4}$, Chih-Yu Yang ${ }^{1,4}$ \\ and Wen-Sheng Liu ${ }^{4,6}$
}

\begin{abstract}
Background: The renin-angiotensin-aldosterone system (RAAS) plays an important role in the progression of chronic kidney disease (CKD). Although dual RAAS inhibition results in worse renal outcomes than monotherapy in high risk type 2 diabetes patients, the effect of dual RAAS inhibition in patients with non-DM CKD is unclear. The aim of this study was to evaluate the potential renoprotective effect of add-on direct renin inhibitor in non-DM CKD patients.

Methods: We retrospectively enrolled 189 non-DM CKD patients who had been taking angiotensin II receptor blockers (ARBs) for more than six months. Patients were divided into an add-on aliskiren group and an ARB monotherapy group. The primary outcomes were a decline in glomerular filtration rate (GFR) and a reduction in urinary protein-to-creatinine ratio at six months.

Results: The baseline characteristics of the two groups were similar. Aliskiren $150 \mathrm{mg}$ daily reduced the urinary protein-to-creatinine ratio by $26 \%$ (95\% confidence interval, 15 to $37 \% ; p<0.001)$. The decline in GFR was smaller in the add-on aliskiren group ( -2.1 vs. $-4.0 \mathrm{ml} / \mathrm{min}, \mathrm{p}=0.038$ ). Add-on aliskiren had a neutral effect on serum potassium in the non-DM CKD patients. In subgroup analysis, the proteinuria-reducing effect of aliskiren was more prominent in patients with a GFR less than $60 \mathrm{ml} / \mathrm{min}$, and in patients with a urinary protein-to-creatinine ratio greater than 1.8. The effect of aliskiren in retarding the decline in GFR was more prominent in patients with hypertensive nephropathy than in those with glomerulonephritis.
\end{abstract}

Conclusion: Add-on direct renin inhibitor aliskiren (150 mg daily) safely reduced proteinuria and attenuated the decline in GFR in the non-DM CKD patients who were receiving ARBs.

Keywords: Aliskiren, Direct renin inhibitor, Proteinuria, CKD

\section{Background}

The pathogenesis of chronic kidney disease is multifactorial, and the renin-angiotensin aldosterone system (RAAS) is known to play an important role. The RAAS is the best known regulator of blood pressure (BP), fluid and electrolyte balance through coordinated effects on the heart, blood vessels, and kidneys [1]. When over-activated, the

\footnotetext{
* Correspondence: syli@vghtpe.gov.tw

${ }^{\dagger}$ Equal contributors

'Division of Nephrology, Department of Medicine, Taipei Veterans General Hospital, Taipei, Taiwan

${ }^{2}$ Institute of Clinical of Medicine, National Yang-Ming University, Taipei, Taiwan

Full list of author information is available at the end of the article
}

RAAS activates a number of pathways and contributes to the onset and progression of chronic renal damage [2]. Proteinuria is one of the most common findings in chronic kidney disease (CKD) [3]. The amount of urine protein is positively associated with glomerulopathy and tubulointerstitium damage, and is the strongest prognostic factor for renal outcomes in CKD patients $[4,5]$. Inhibition of the RAAS by angiotensin-converting enzyme (ACE) inhibitors or angiotensin II receptor blockers (ARBs) prevents the progression of CKD in both diabetic and non-DM patients [6-12]. However, in patients with vascular disease or high risk diabetes, dual RAAS inhibition through a combination of ACE inhibitors and ARBs is associated with more

\section{Biomed Central}


adverse events without an increase in benefits compared to monotherapy, as shown by the ONTARGET trial [12]. The ALTITUDE clinical trial attempted to evaluate the potential renoprotective effect of the add-on direct renin inhibitor (DRI) aliskiren in high risk type $2 \mathrm{DM}$ patients who were already taking ACE inhibitors or ARBs, [13] however the trial was terminated early because of adverse events. These two clinical trials clearly indicated that dual RAAS inhibition is not suitable for high risk type 2 DM patients. In contrast, the effect of dual RAAS inhibition in non-DM patients was still unclear. Although the use of add-on DRIs has been shown to be renoprotective in various animal models of non-DM kidney disease, [12,14-17] the clinical implications are still unclear. The aim of current study, therefore, was to evaluate the potential renoprotective effect of the add-on direct renin inhibitor aliskiren in non-DM CKD patients who were already receiving ARB treatment.

\section{Methods}

\section{Study population}

This retrospective study was approved by the Institutional Review Board of Taipei Veterans General Hospital. We enrolled patients who were included in the chronic kidney disease care program at Taipei Veterans General Hospital between March 1, 2010 and April 30, 2011. The CKD care program was launched by the Taiwan Health Promotion Bureau [18]. This program organizes nephrologists, renal nurses and dieticians into a multidisciplinary team to care for CKD patients with the goals of education and clinical protocols. Every patient undergoes regular follow-up visits with clinical evaluation, laboratory examinations, nursing and dietary education every 1-3 months. The CKD care program improves the quality of pre-ESRD care and reduces medical costs [19].

\section{Inclusion and exclusion criteria}

Patients in the CKD care program who were hypertensive, older than 18 years, had non-DM CKD and proteinuria (defined by a spot urinary protein-to-creatinine ratio of $>300 \mathrm{mg}$ per gram), and had been taking ARBs for more than 90 days were enrolled. The exclusion criteria were known diabetes mellitus, a urinary protein-to-creatinine ratio of more than $3500 \mathrm{mg}$ per gram, an estimated glomerular filtration rate (GFR) of less than $15 \mathrm{ml}$ per minute per $1.73 \mathrm{~m} 2$ of body-surface area, [20] chronic urinarytract infections, a serum potassium level greater than $6.0 \mathrm{mmol}$ per liter at the time of enrollment, and kidney transplant recipients. Patients who received add-on aliskiren $150 \mathrm{mg}$ daily were defined as the aliskiren group, and the remainders were defined as the ARB monotherapy group. In the aliskiren group, patients who had not been taking aliskiren for more than 90 days were also excluded.

\section{Measurement of urine protein and renal function}

The patients were examined initially and at 8, 16, and 24 weeks. Blood pressure, concomitant medications, the results of laboratory tests, and urinary protein-to-creatinine ratios were assessed at each visit. The urinary protein concentration was determined by immunoturbidimetry, and the creatinine concentration was determined by means of the Jaffe reaction. The Modification of Diet in Renal Disease (MDRD) formula was used to estimate the glomerular filtration rate [20]. All of the other laboratory variables were also measured centrally in a CAP qualified laboratory. The primary outcome was the percentage reduction in the urinary protein-to-creatinine ratio and the secondary outcome was the eGFR decline from baseline to the end of follow-up.

\section{Statistical analysis}

Normally distributed continuous data are expressed as means \pm standard deviations. Numeric data with non-normal distributions are expressed as medians and interquartile ranges. To compare the parameters among each group, Pearson $\chi^{2}$ tests were carried out for categorical variables, and the independent $t$-test and Mann-Whitney $U$ test were used for parametric and nonparametric continuous variables,

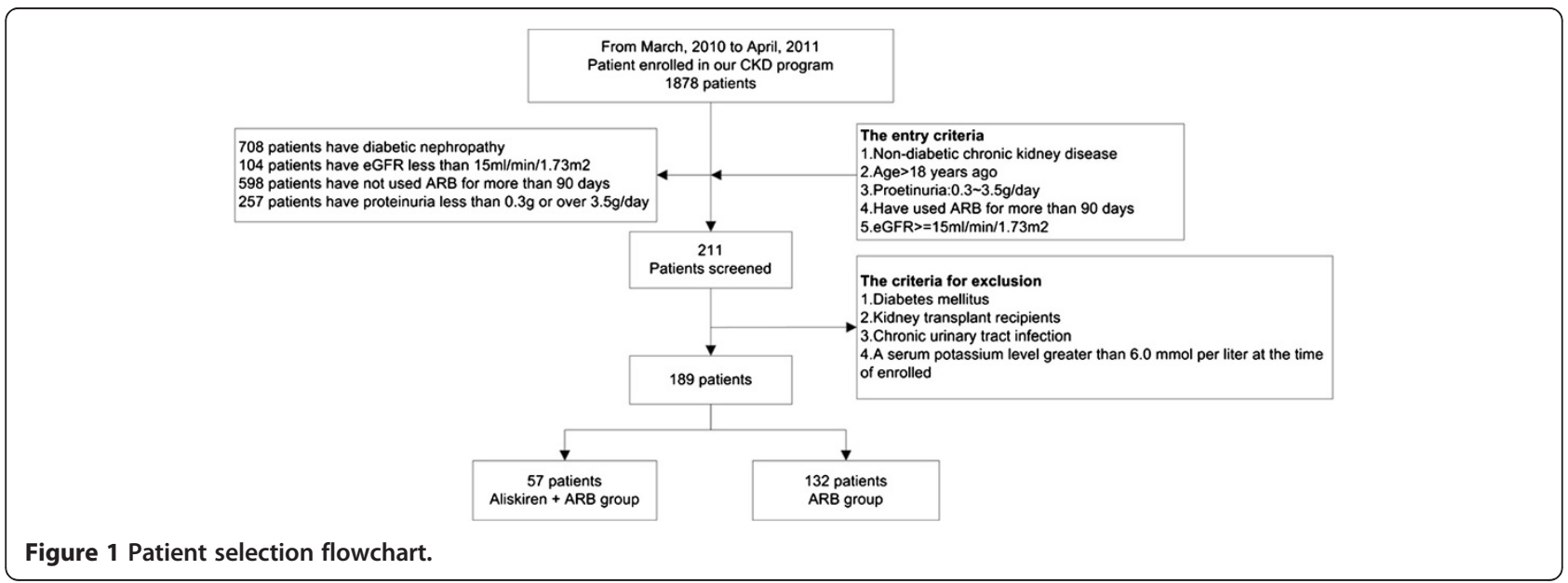


Table 1 Baseline patient characteristics

\begin{tabular}{|c|c|c|c|}
\hline Characteristic & Aliskiren + ARB Group & ARB Group & $P$ value \\
\hline & $\mathrm{N}=57$ & $N=132$ & \\
\hline \multicolumn{4}{|l|}{ Demographic } \\
\hline Age & $63.9 \pm 19.3$ & $66.5 \pm 15.4$ & 0.367 \\
\hline Male gender & $61.4 \%(n=35)$ & $68.9 \%(n=91)$ & 0.313 \\
\hline \multicolumn{4}{|l|}{ Clinical } \\
\hline Body-mass index & $24.8 \pm 3.9$ & $25.2 \pm 3.7$ & 0.548 \\
\hline \multicolumn{4}{|l|}{ Mean sitting blood pressure-mmHg } \\
\hline Systolic & $134.9 \pm 16.6$ & $131.0 \pm 14.0$ & 0.123 \\
\hline Diastolic & $77.2 \pm 10.8$ & $77.4 \pm 10.5$ & 0.135 \\
\hline Urine protein-to-creatinine ratio & $1.84(0.89 \sim 2.77)$ & $1.81(0.84 \sim 2.78)$ & 0.723 \\
\hline Estimated glomerular filtration rate $\mathrm{ml} / \mathrm{min} / 1.73 \mathrm{~m} 2$ & $50.9 \pm 31.1$ & $42.5 \pm 19.9$ & 0.062 \\
\hline Hemoglobin (g/liter) & $12.0 \pm 1.9$ & $11.8 \pm 1.9$ & 0.525 \\
\hline Chronic kidney disease stage & & & 0.173 \\
\hline Stage I & $10.5 \%(n=6)$ & $4.5 \%(n=6)$ & \\
\hline Stage II & $17.5 \%(n=10)$ & $7.6 \%(n=10)$ & \\
\hline Stage IIIA & $14.0 \%(n=8)$ & $23.5 \%(n=31)$ & \\
\hline Stage IIIB & $28.1 \%(n=16)$ & $36.4 \%(n=48)$ & \\
\hline Stage IV & $29.8 \%(n=17)$ & $28.0 \%(n=37)$ & \\
\hline Etiology & & & 0.917 \\
\hline Hypertensive nephropathy & $36.8 \%(n=21)$ & $34.1 \%(n=45)$ & \\
\hline Chronic glomerulonephritis & $43.9 \%(n=25)$ & $47.0 \%(n=62)$ & \\
\hline Interstitial nephritis & $19.3 \%(n=11)$ & $18.9 \%(n=25)$ & \\
\hline Triglycerides (mg/dl) & $146.3 \pm 100.2$ & $133.0 \pm 79.4$ & 0.369 \\
\hline \multicolumn{4}{|l|}{ Cholesterol (mg/dl) } \\
\hline Total & $198.9 \pm 52.4$ & $183.7 \pm 45.7$ & 0.062 \\
\hline Low-density lipoprotein & $116.4 \pm 38.8$ & $112.4 \pm 37.7$ & 0.567 \\
\hline High-density lipoprotein & $51.8 \pm 14.0$ & $48.6 \pm 17.3$ & 0.309 \\
\hline Serum potassium (mmol/liter) & $4.2 \pm 0.5$ & $4.4 \pm 0.6$ & 0.037 \\
\hline \multicolumn{4}{|l|}{ Antihypertensive drugs received at baseline } \\
\hline Calcium-channel blocker & $52.6 \%(n=30)$ & $43.9 \%(n=58)$ & 0.272 \\
\hline Beta-blocker & $21.1 \%(n=12)$ & $15.9 \%(n=21)$ & 0.393 \\
\hline Diuretic & $35.1 \%(n=20)$ & $47.0 \%(n=62)$ & 0.130 \\
\hline Alpha-blocker & $14.0 \%(n=8)$ & $5.3 \%(n=7)$ & 0.042 \\
\hline
\end{tabular}

respectively. To compare the parameters within groups, the paired $T$-test and Wilcoxon test were used for parametric and nonparametric continuous variables, respectively. All probabilities were two tailed. A $p$-value less than 0.05 was considered significant.

\section{Results}

Add on aliskiren attenuated urinary protein and decline in estimated glomerular filtration rate in non-DM CKD patients

Fifty-seven patients in the aliskiren group and 132 patients in the ARB monotherapy group were enrolled in this study
(Figure 1). Among the enrolled patients, 78.9\% took Losar$\tan 160 \mathrm{mg}$ and $21.1 \%$ took irbesartan $300 \mathrm{mg}$ daily, there are no difference between aliskiren and ARB alone group in ARB type and dosage. The baseline demographic data including age, sex, mean urinary protein-to-creatinine ratio, estimated glomerular filtration rate (eGFR), and blood pressure of the two groups were comparable (Table 1).

By the end of the study, compared with baseline, there was no significant change of mean blood pressure between the two groups $(-1.9 \mathrm{mmHg}$ in the aliskiren group and $-1.3 \mathrm{mmHg}$ in the ARB monotherapy group, $\mathrm{p}=0.802$ ). 


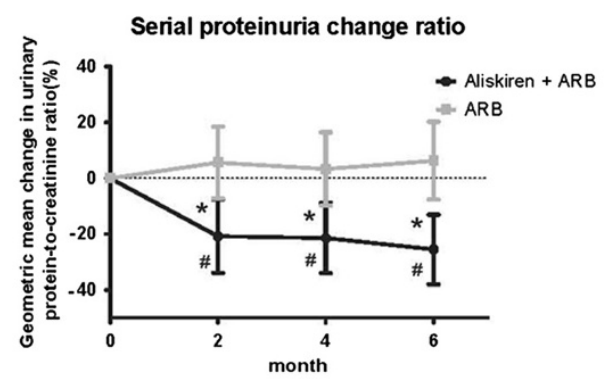

Compare with ARB monotherapy group. Mann-Whitney Utest $p<0.05$ \# Compare whth baseline, Paired $-t$ test $p<0.05$

Delta eGFR ratio Mann-Whitney U test $p=0.09$

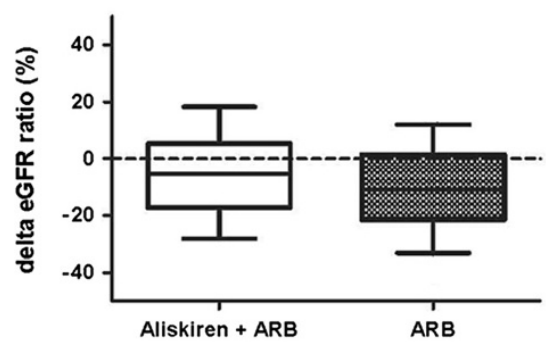

Serial absoulte proteinuria level

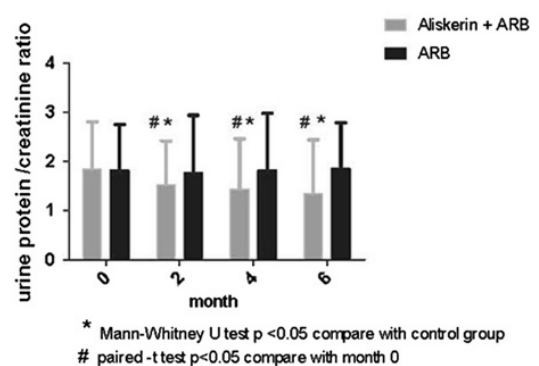

Delta eGFR, Mann-Whitney $U$ test $p=0.038$

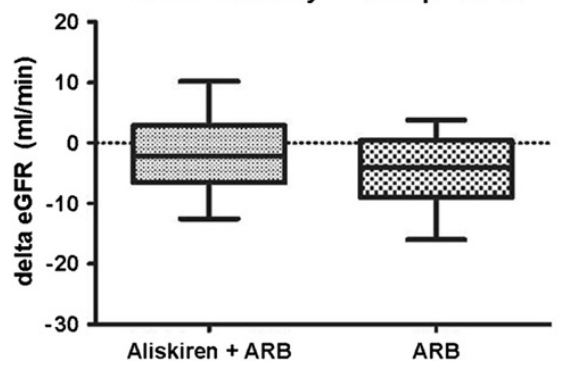

Figure 2 Serial change of proteinuria and eGFR in the two groups. In the 6-month study period, add-on aliskiren reduced the urinary protein-to-creatinine ratio and slowed down the decline in GFR decline. ${ }^{*}$ Compared with the ARB group, Mann-Whitney $U$ test $p<0.05$; \# Compared with baseline, paired $t$ test $p<0.05$.

After the 6 months follow-up period, add-on aliskiren treatment had reduced the mean urinary protein-to-creatinine ratio by $26 \%$ (95\% confidence interval $[\mathrm{CI}], 15-37 \%$; $\mathrm{p}<0.001$ ), while there was no significant change in the amount of urine protein in the ARB monotherapy group. The decline in eGFR was slower in the aliskiren group compared to the ARB monotherapy group ( -2.1 vs. $-4.0 \mathrm{ml} / \mathrm{min}$, $\mathrm{p}=0.038$ ) (Figure 2). With regards to the risk of hyperkalemia, add-on aliskiren had a neutral effect on serum potassium. No stroke or myocardial infarction events occurred during the study period in either group.

\section{Subgroup analysis for anti-proteinuric effect and retarded \\ GFR decline rate}

To evaluate the anti-proteinuric effect of aliskiren in different patient populations, we performed subgroup analysis stratified by gender, baseline eGFR and urine protein. The proteinuria-reducing effect of add-on aliskiren was more prominent in males, and in patients with a GFR less than $60 \mathrm{ml} / \mathrm{min}$. Aliskiren had an anti-proteinuric effect in non-DM CKD patients regardless of the urinary protein amount, but the effect was more prominent in patients with heavier proteinuria (Figure 3). In subgroup analysis for a decline in eGFR, add-on aliskiren retarded the decline in GFR in patients with hypertensive nephropathy $(\mathrm{p}=0.037)$ but not in patient with glomerulonephritis $(\mathrm{p}=0.40)$.

\section{Discussion}

In diabetic and non-DM nephropathy, blocking the RAAS is the mainstay of therapy to prevent progression of renal disease [21,22]. ACE inhibitors and ARB have been shown to have a renoprotective effect and reduced morbidity and mortality in patients with chronic kidney disease [22,23] However, the strategy of dual RAAS inhibition seems to have different clinical impacts in diabetic and non-diabetic CKD patients. In high risk and type 2 diabetic CKD patients, a combination of ACE inhibitors and ARBs is associated with more adverse renal events [12]. Although add-on DRIs have been shown to reduce urinary protein in DM nephropathy patients who are receiving ARBs, [24] a large-scale clinical trial evaluating the effect of add-on DRI aliskiren $300 \mathrm{mg}$ in high risk DM patients who were taking ACI inhibitors or ARBs [13] was terminated early because of increased adverse events, including non-fatal stroke, hypotension, hyperkalemia and renal complications. However, the potential renoprotective effect of dual RAAS inhibition has not been investigated in non-DM CKD patients. In the current study, we found that add-on DRI aliskiren $150 \mathrm{mg}$ daily safely reduced proteinuria and attenuated the decline in GFR in non-DM CKD patients who were already taking ARBs.

The major difference between the ALTITUDE and the current study are the patient population and the dosage of aliskiren. ALTITUDE study included patients taking ACE 

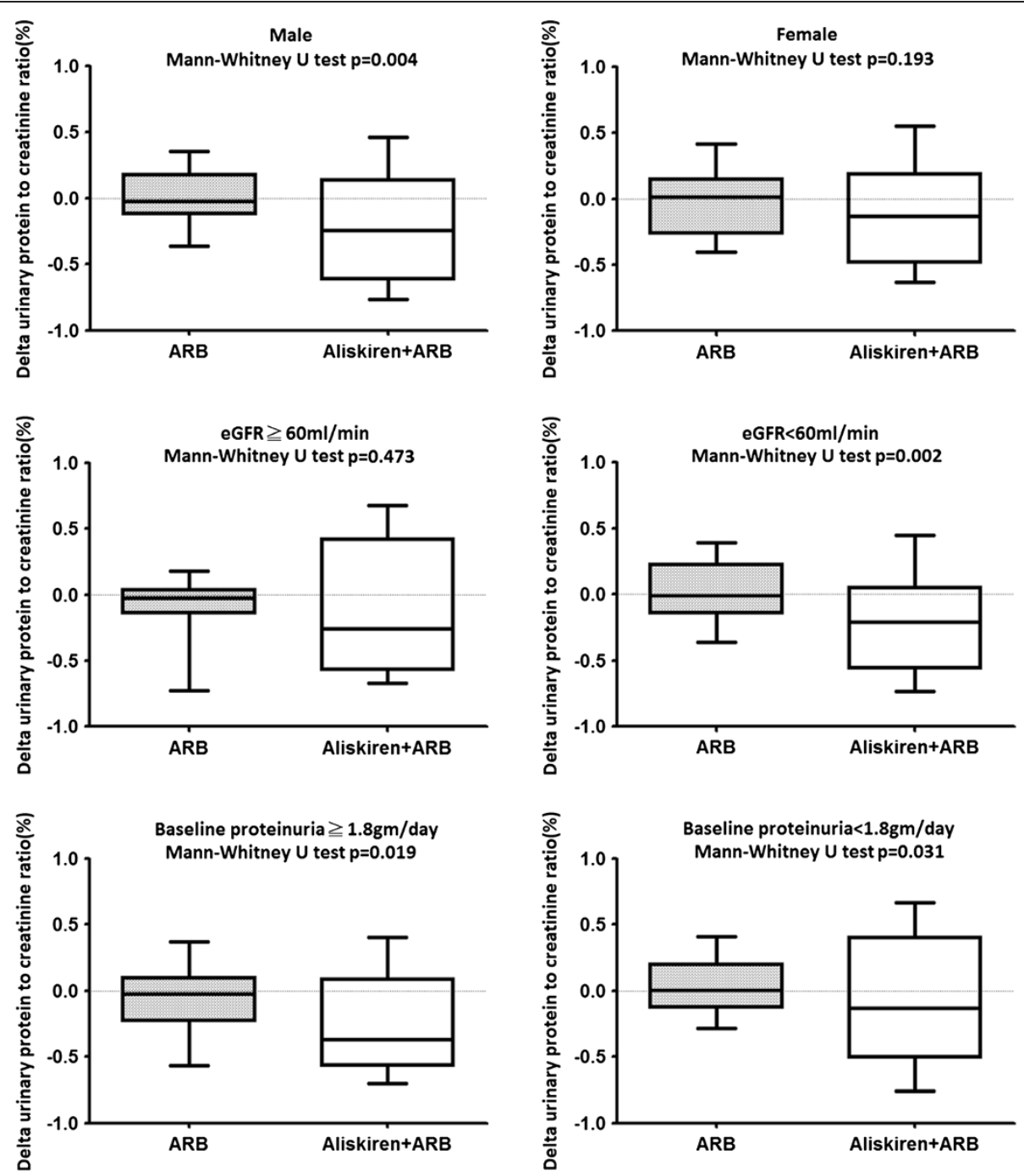

Figure 3 Subgroup analysis for the anti-proteinuric effect of aliskiren. The anti-proteinuric effect of add-on aliskiren was analyzed by gender, baseline eGFR and proteinuria.

inhibitors but the AVOID study and the current study did not. Because ACE inhibitor related cough is prevalent in Asians, most patients who need RAAS inhibition receive ARBs rather than ACE inhibitors in our CKD program, thus, we enrolled patients taking ARBs in current study. In Taiwan, the medical expenditure is paid by National Health Insurance Program, which covers 99.9\% Taiwanese population. Currently, aliskiren can be claimed $150 \mathrm{mg}$ (1 tablet) daily. In contrast, patients in the ALTITUDE trial took aliskiren $300 \mathrm{mg}$ daily, and have a higher possibility of hyperkalemia and other side effects.

Similar with previous studies on diabetic nephropathy, $[25,26]$ our results showed that the proteinuria reducing effect of add-on aliskiren was more prominent in the high risk group. We also found that the anti-proteinuric effect was more prominent in patients with an eGFR of less than 60 $\mathrm{ml} / \mathrm{min}$, and in patients with a urinary protein-to-creatinine ratio greater than 1.8. In addition, we found that add-on aliskiren attenuated the decline in GFR in hypertensive nephropathy patients. Although not reaching statistical significance, our results suggest that add-on aliskiren may have a greater renoprotective effect in early stage CKD patients (GFR $>60$ $\mathrm{ml} / \mathrm{min}$ and not profound proteinuria). There was no significant change in mean blood pressure after add-on aliskiren $(p=0.263)$, indicating that add-on DRIs have a renoprotective effect in non-DM CKD patients beyond a blood pressure lowering effect. This finding was also confirmed in several non-DM CKD animal models $[14,27,28]$. In the AVOID trial, the reduction in systolic blood pressure was only $2 \mathrm{mmHg}$ after add-on aliskiren treatment in the study group.In ONGARTET study, combine RAAS blockade also has marginal effect on the reduction of blood pressure. The patients in the current study took half of the dosage of aliskiren than the patients in the AVOID study. This may 
explain why aliskiren had less of a blood pressure lowering effect in our study. Although renin inhibitor monotherapy provides a dose-dependent BP lowering effect, [29] our study and the AVOID trial showed that add-on aliskiren in CKD patients receiving ARBs had a lesser effect on blood pressure.

The renoprotective effect of add-on aliskiren in patients with non-DM CKD has been evaluated in clinical settings in several studies, however all have had limitations. Without a control group, Lopez et al. and Tang et al. demonstrated that add-on aliskiren reduced urinary protein in kidney transplant recipients $(n=12)$ and immunoglobulin A nephropathy patients $(n=25)$, respectively [30] [31]. A prospective trial conducted by Tsukasa Nakamura et al. found that combination therapy with aliskiren and ARBs decreased proteinuria in non-DM CKD patients more effectively than monotherapy alone, however their findings did not reach statistical significance due to the limited number of patients ( $\mathrm{n}=12$ in each group) [32]. By studying 189 non diabetic CKD patients, the present study clearly shows that aliskiren reduced proteinuria in patients with non-DM chronic kidney disease who were receiving ARBs. Add-on aliskiren (150 mg daily) for six months reduced the mean urinary protein-to-creatinine ratio by $26 \%$.

There are several limitations to the current study. First, it was not a randomized prospective control trial, and the results may have been biased by patient selection and data retrieval. Second, the 6-month study period was not long enough to reveal uncommon side effects. Third, plasma renin activity was not examined in our study, thus, it is unknown whether changes of plasma renin activity are correlated with the renoprotective effect of aliskiren. Even with these limitations, we believe our results are reliable and suggest important clinical implications. The patients enrolled in this study were selected from a registered CKD program, with frequent follow-up visits and the best clinical care, and their medical data were complete. To the best of our knowledge, the current study is the largest scale study to evaluate the effect of an add-on direct renin inhibitor in non-DM CKD patients.

\section{Conclusion}

In conclusion, we found that add-on aliskiren (150 mg daily) in non-DM CKD patients already receiving ARBs safely reduced proteinuria and attenuated the decline in GFR. The anti-proteinuric effect was more prominent in patients with an estimated glomerular filtration rate less than $60 \mathrm{ml} / \mathrm{min}$, and in patients with a urinary protein-to-creatinine ratio greater than 1.8. Further prospective studies are necessary to confirm these findings.

\section{Competing interest}

The authors declare that they have no competing interests.

\section{Authors' contributions}

SY Li and YT Chen designed research, performed, and wrote the paper; WC Yang and DC Tarng directed the study; CC Lin, CY Yang, and WS Liu interpreted the data. All authors read and approved the final manuscript.

\section{Acknowledgements}

This study was supported by a grant from Taipei Veterans General Hospital, Taipei, Taiwan (VGH_V100-B30). The authors thank physicians and nurses of the CKD care program for the collection of data.

\section{Author details}

${ }^{1}$ Division of Nephrology, Department of Medicine, Taipei Veterans General Hospital, Taipei, Taiwan. ${ }^{2}$ Institute of Clinical of Medicine, National Yang-Ming University, Taipei, Taiwan. ${ }^{3}$ Department of Medicine, Taipei City Hospital Heping Fuyou Branch, Taipei, Taiwan. ${ }^{4}$ School of Medicine, National YangMing University, Taipei, Taiwan. ${ }^{5}$ Department and Institute of Physiology, National Yang-Ming University, Taipei, Taiwan. ${ }^{6}$ Division of Nephrology, Department of Medicine, Taipei City Hospital, Zhong-Xing Branch, Taipei, Taiwan.

Received: 2 February 2012 Accepted: 12 July 2012

Published: 23 August 2012

\section{References}

1. Schroten NF, Gaillard CA, van Veldhuisen DJ, Szymanski MK, Hillege HL, de Boer RA: New roles for renin and prorenin in heart failure and cardiorenal crosstalk. Heart Fail Rev 2012, 17(2):191-201.

2. Remuzzi G, Perico N, Macia M, Ruggenenti P: The role of reninangiotensin-aldosterone system in the progression of chronic kidney disease. Kidney Int Supp/ 2005, 99:S57-S65.

3. Remuzzi G, Bertani T: Pathophysiology of progressive nephropathies. N Engl J Med 1998, 339(20):1448-1456.

4. Taft JL, Nolan CJ, Yeung SP, Hewitson TD, Martin Fl: Clinical and histological correlations of decline in renal function in diabetic patients with proteinuria. Diabetes 1994, 43(8):1046-1051.

5. Ziyadeh FN, Goldfarb S: The renal tubulointerstitium in diabetes mellitus. Kidney Int 1991, 39(3):464-475.

6. The GISEN Group (Gruppo Italiano di Studi Epidemiologici in Nefrologia): Randomised placebo-controlled trial of effect of ramipril on decline in glomerular filtration rate and risk of terminal renal failure in proteinuric, non-diabetic nephropathy. Lancet 1997, 349(9069):1857-1863.

7. Titan SM, M. Vieira J J, Dominguez WV, Barros RT, Zatz R: ACEI and ARB combination therapy in patients with macroalbuminuric diabetic nephropathy and low socioeconomic level: a double-blind randomized clinical trial. Clinical nephrology 2011 Oct; 76(4):273-83.

8. Hull S, Dreyer G, Badrick E, Chesser A, Yaqoob MM: The relationship of ethnicity to the prevalence and management of hypertension and associated chronic kidney disease. BMC Nephrology 2011, 12:41.

9. Maschio G, Alberti D, Janin G, Locatelli F, Mann JF, Motolese M, Ponticelli C, Ritz E, Zucchelli P: Effect of the angiotensin-converting-enzyme inhibitor benazepril on the progression of chronic renal insufficiency. The Angiotensin-Converting-Enzyme Inhibition in Progressive Renal Insufficiency Study Group. N Engl J Med 1996, 334(15):939-945.

10. Hou FF, Zhang $X$, Zhang GH, Xie D, Chen PY, Zhang WR, Jiang JP, Liang M, Wang GB, Liu ZR, et al: Efficacy and safety of benazepril for advanced chronic renal insufficiency. N Engl J Med 2006, 354(2):131-140.

11. Parving $\mathrm{HH}$, Lehnert $\mathrm{H}$, Brochner-Mortensen J, Gomis R, Andersen S, Arner P: Effect of irbesartan on the development of diabetic nephropathy in patients with type 2 diabetes. Ugeskr Laeger 2001, 163(40):5519-5524.

12. Yusuf S, Teo KK, Pogue J, Dyal L, Copland I, Schumacher H, Dagenais G, Sleight $P$, Anderson $C$ : Telmisartan, ramipril, or both in patients at high risk for vascular events. N Engl J Med 2008, 358(15):1547-1559.

13. Parving HH, Brenner BM, McMurray JJ, de Zeeuw D, Haffner SM, Solomon SD, Chaturvedi N, Ghadanfar M, Weissbach N, Xiang Z, et al: Aliskiren Trial in Type 2 Diabetes Using Cardio-Renal Endpoints (ALTITUDE): rationale and study design. Nephrology, dialysis, transplantation: official publication of the European Dialysis and Transplant Association - European Renal Association 2009, 24(5):1663-1671.

14. Gross O, Girgert R, Rubel D, Temme J, Theissen S, Muller GA: Renal protective effects of aliskiren beyond its antihypertensive property in a mouse model of progressive fibrosis. Am J Hypertens 2011, 24(3):355-361. 
15. Bakris GL, Siomos M, Richardson D, Janssen I, Bolton WK, Hebert L, Agarwal R, Catanzaro D: ACE inhibition or angiotensin receptor blockade: impact on potassium in renal failure. VAL-K Study Group. Kidney Int 2000, 58(5):2084-2092.

16. Adler SG, Feld S, Striker L, Striker G, LaPage J, Esposito C, Aboulhosn J, Barba L, Cha DR, Nast CC: Glomerular type IV collagen in patients with diabetic nephropathy with and without additional glomerular disease. Kidney Int 2000, 57(5):2084-2092.

17. Sun CY, Cherng WJ, Jian HZ, Hsu HH, Wu IW: Hsu HJ. Wu MS: Aliskiren reduced renal fibrosis in mice with chronic ischemic kidney injury-beyond the direct renin inhibition. Hypertens Res; 2011.

18. Chen N, Hsu CC, Yamagata K, Langham R: Challenging chronic kidney disease: experience from chronic kidney disease prevention programs in Shanghai, Japan, Taiwan and Australia. Nephrology (Carlton) 2010, 15(Suppl 2):31-36.

19. Wei SY, Chang YY, Mau LW, Lin MY, Chiu HC, Tsai JC, Huang CJ, Chen HC, Hwang SJ: Chronic kidney disease care program improves quality of pre-end-stage renal disease care and reduces medical costs. Nephrology (Carlton) 2010, 15(1):108-115.

20. Levey AS, Bosch JP, Lewis JB, Greene T, Rogers N, Roth D: A more accurate method to estimate glomerular filtration rate from serum creatinine: a new prediction equation. Modification of Diet in Renal Disease Study Group. Ann Intern Med 1999, 130(6):461-470.

21. Ruggenenti P, Perna A, Gherardi G, Garini G, Zoccali C, Salvadori M, Scolari F, Schena FP, Remuzzi G: Renoprotective properties of ACE-inhibition in non-diabetic nephropathies with non-nephrotic proteinuria. Lancet 1999, 354(9176):359-364.

22. Lewis EJ, Hunsicker LG, Clarke WR, Berl T, Pohl MA, Lewis JB, Ritz E, Atkins $R C$, Rohde R, Raz I: Renoprotective effect of the angiotensin-receptor antagonist irbesartan in patients with nephropathy due to type 2 diabetes. N Engl J Med 2001, 345(12):851-860.

23. Porter AM: Ramipril in non-diabetic renal failure (REIN study) Ramipril Efficiency in Nephropathy Study. Lancet 1997, 350(9079):736. author reply 736-737.

24. Parving HH, Persson F, Lewis JB, Lewis EJ, Hollenberg NK: Aliskiren combined with losartan in type 2 diabetes and nephropathy. N Engl J Med 2008, 358(23):2433-2446.

25. Persson F, Lewis JB, Lewis EJ, Rossing P, Hollenberg NK, Parving HH: Impact of baseline renal function on the efficacy and safety of aliskiren added to losartan in patients with type 2 diabetes and nephropathy. Diabetes Care 2010, 33(11):2304-2309.

26. Tang SC, Leung JC, Lai KN: The kallikrein-kinin system. Contrib Nephrol 2011, 170:145-155.

27. Wu WP, Chang CH, Chiu YT, Ku CL, Wen MC, Shu KH, Wu MJ: A reduction of unilateral ureteral obstruction-induced renal fibrosis by a therapy combining valsartan with aliskiren. Am J Physiol Renal Physiol 2010, 299(5):F929-F941.

28. Choi DE, Jeong JY, Lim BJ, Chang YK, Na KR, Shin YT, Lee KW: Aliskiren ameliorates renal inflammation and fibrosis induced by unilateral ureteral obstruction in mice. JUrol 2011, 186(2):694-701.

29. Weir MR, Bush C, Anderson DR, Zhang J, Keefe D, Satlin A: Antihypertensive efficacy, safety, and tolerability of the oral direct renin inhibitor aliskiren in patients with hypertension: a pooled analysis. J Am SocHypertens 2007, 1(4):264-277.

30. López V, Martin M, Cobelo C, Aranda P, Cabello M, Sola E, Gutierrez C, Burgos D, Martínez D, Hernandez D: Renin-angiotensin system dual blockade using angiotensin receptor plus aliskiren decreases severe proteinuria in kidney transplant recipients. Transplant Proc 2010, 42(8):2883-2885.

31. Tang SC, Lin M, Tam S, Au WS, Ma MK, Yap DY, Ho YW, Lai KN: Aliskiren combined with losartan in immunoglobulin A nephropathy: an open-labeled pilot study. Nephrol Dial Transplant 2012, 27(2):613-618.

32. Nakamura T, Sato E, Amaha M, Kawagoe Y, Maeda S, Yamagishi SI: Addition of aliskiren to olmesartan ameliorates tubular injury in chronic kidney disease patients partly by reducing proteinuria. J Renin Angiotensin Aldosterone Syst 2011.

\section{doi:10.1186/1471-2369-13-89}

Cite this article as: Chen et al: Effect of add-on direct renin inhibitor aliskiren in patients with non-diabetes related chronic kidney disease. BMC Nephrology 2012 13:89.

\section{Submit your next manuscript to BioMed Central and take full advantage of:}

- Convenient online submission

- Thorough peer review

- No space constraints or color figure charges

- Immediate publication on acceptance

- Inclusion in PubMed, CAS, Scopus and Google Scholar

- Research which is freely available for redistribution 